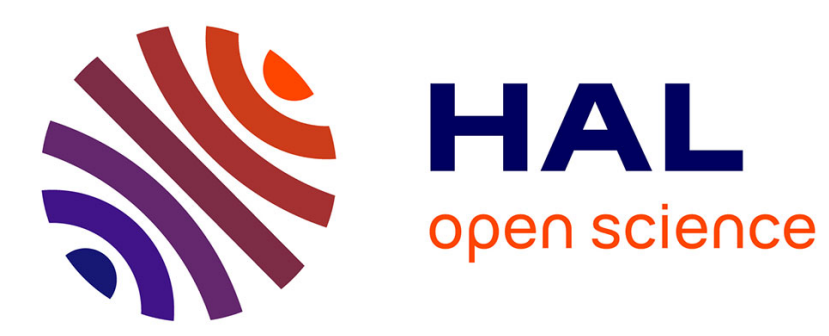

\title{
Learning through Multimedia
}

Roy D. Pea

\section{To cite this version:}

Roy D. Pea. Learning through Multimedia. IEEE Computer Graphics and Applications, 1991, 11(4), pp.58-66. hal-00190567

\section{HAL Id: hal-00190567 https://telearn.archives-ouvertes.fr/hal-00190567}

Submitted on 23 Nov 2007

HAL is a multi-disciplinary open access archive for the deposit and dissemination of scientific research documents, whether they are published or not. The documents may come from teaching and research institutions in France or abroad, or from public or private research centers.
L'archive ouverte pluridisciplinaire HAL, est destinée au dépôt et à la diffusion de documents scientifiques de niveau recherche, publiés ou non, émanant des établissements d'enseignement et de recherche français ou étrangers, des laboratoires publics ou privés. 


\title{
Compultertirgraphics
}

\section{Learning through Multimedia}

\author{
Roy D. Pea
}

Institute for Research on Learning 


\section{Dolphins are currently threatened by abusive fishing techniques.}

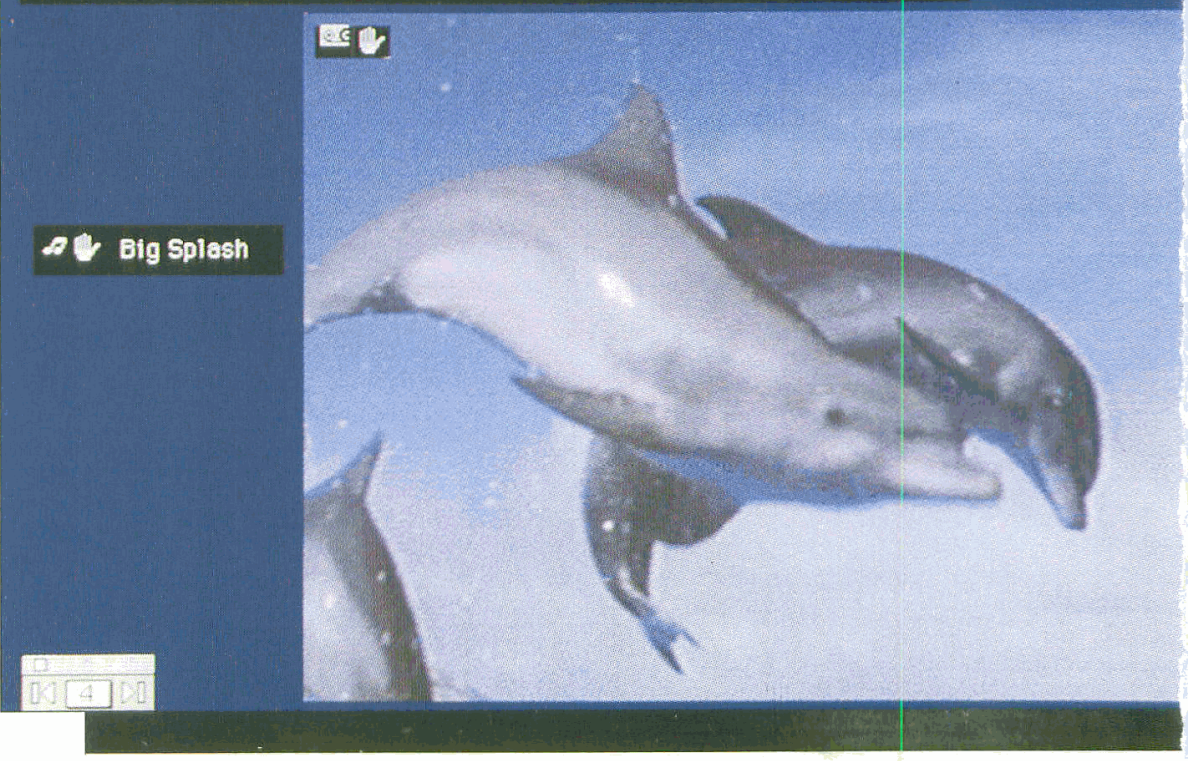

\section{Learning through Multimedia}

Roy D. Pea

Institute for Research on Learning

Teaching both new subject matter and new technology, Multimedia Works encourages students to create multimedia compositions that explain, tell a story, or persuade.

\begin{abstract}
A
s multimedia technology proliferates, we must explore some central learning questions. Whereas movies separate directors and viewers, the technology of interactive multimedia can unite creators and viewers in much the same way as the technology of writing unites writers and readers. Society might come to regard multimedia literacy as essential as writing is today. Anticipating this future, the Multimedia Works Project focuses on enabling students to create and use multimedia documents. Our major challenge has been to design tools that young learners can use to create multimedia communications. These tools enable students to become multimedia composers, not just consumers. (I use the term "composer" rather than "author" because it correctly implies that creating multimedia involves designing an arrangement of parts.)

Learners need to control computer-controlled multimedia to communicate their own understanding of information. Multimedia objects (text, pictures, video clips, and so forth) are important building blocks for developing and conveying a student's understanding for several reasons:
\end{abstract}


1. Multimedia communication is similar to face-to-face communication.

2. Multimedia is less restricted than written text. Many people come to understand text better with broader media support for its interpretation.

3. Multimedia can place abstract concepts in a specific context (for example, refraction in physics might be depicted in a film of lens and light behavior).

4. Multimedia allows for individual differences in preferred sensory channels for learning.

5. Multimedia lets you coordinate diverse external representations (with distinctive strengths) for different perspectives.

Creating multimedia composition tools for young learners is no small challenge. It means more than letling learners make choices among predefined options. Consider how students go about scholarly research. They develop a critical synthesis to summarize literature or film, craft a compelling argument, and carefully weigh pros and cons. In short, they construct meaning from cultural artifacts, a process similar to the composition of multimedia interpretations. Unless students start composing their own multimedia interpretations, multimedia "educational materials" will be "delivered" to students, just as books are now. We might find the 21 st century recapitulating extant problems with texts in education, which promote an "authority-centered" epistemology.

Today's book report or research paper is one place to start thinking about multimedia composing. With these assignments, students typically underuse research resources, are limited to written text as their final product, and lack opportunities for presenting and discussing that product with a critical community (that is, teachers and peers). When we extend these assignments to connect with large, user-extensible multimedia databases, collaborative activities, and interactive presentations to reactive audiences, then we come closer to a culturallybased learning activity centered on students' constructing and communicating their understanding.

Most of multimedia computing in education or business now is what we call chained multimedia rather than integrated multimedia. In chained multimedia, the communication consists of the temporal sequencing of experientially distinct multimedia objects, like an interruptible slide show that accompanies text. A screen of text might contain a button to press that brings up a screen graphic or video sequence on another monitor, which might return to the text, where another button plays an animation, and so forth. Integrated multimedia makes spatial juxtaposition and temporal overlapping of diverse media available. Such integration is evident in the classic audiovisual fusion of sound and image in video and film. ${ }^{\prime}$

It's difficult to create even linear integrated multimedia, and interactive multimedia composition is even more complex. We decided to first resolve problems in linear multimedia composing, then build toward interactive, integrated multimedia. (Hypermedia networks of information, interactive books, and "guided tours" with optional paths raise even more difficult questions. ${ }^{2}$ )

\section{Designing composing tools}

Multimedia composing is a complex cognitive task. Multimedia Works' goal was to support the user's choreographic sequencing of media elements (video clips, text displays, photos, graphics, sound clips, animations) in space and time through a task-transparent interface. Until recently there were so many technical barriers to such choreography that we could not easily see the conceptual issues of integrated multimedia design.

Composing multimedia with existing tools is obviously more complex than writing. But various cognitive technologies for writing are available to support the writer's work: planning and goal-setting, generating and organizing ideas and text, goal

\section{Multimedia is less restricted than written text. Many people come to understand text better with broader media support for its interpretation.}

progress monitoring, text evaluation, and revision. ${ }^{3}$ Researchers have given far less attention to the multidocument search and synthesis activities involved in writing. All these activities are key to multimedia composition.

Multimedia composing resembles film editing, animation, and/or choreography, except that you also want to have computational control over the objects and events you design. Such computational control includes where, when, and how long the objects should be displayed on the screen(s). These issues are largely treated as defaults in writing, but they are important variable properties in multimedia.

We knew that multimedia composing could be made much simpler by designing more congenial representations for creating, transforming, controlling, and viewing media elements. Multimedia composers need scores for coordinating displays of sound, image, and text over the space of display screens and the time of "playing" a composition. ${ }^{4}$ These scores should provide alternate views on the structure of multimedia compositions, that is, making patterns of media dominance or co-occurrence more visible.

In another article, Mills and $I^{5}$ stated that multimedia composing tasks involve operations-cognitive and physical-on a number of hierarchically nested units. For example, a multimedia composition might constitute a story composed of episodes and events. Events consist of dynamic arrangements of scenes that express object relations. We found this scheme not wholly satisfying in practice. It's far more important to consider the composing medium's material substrate (properties of file 


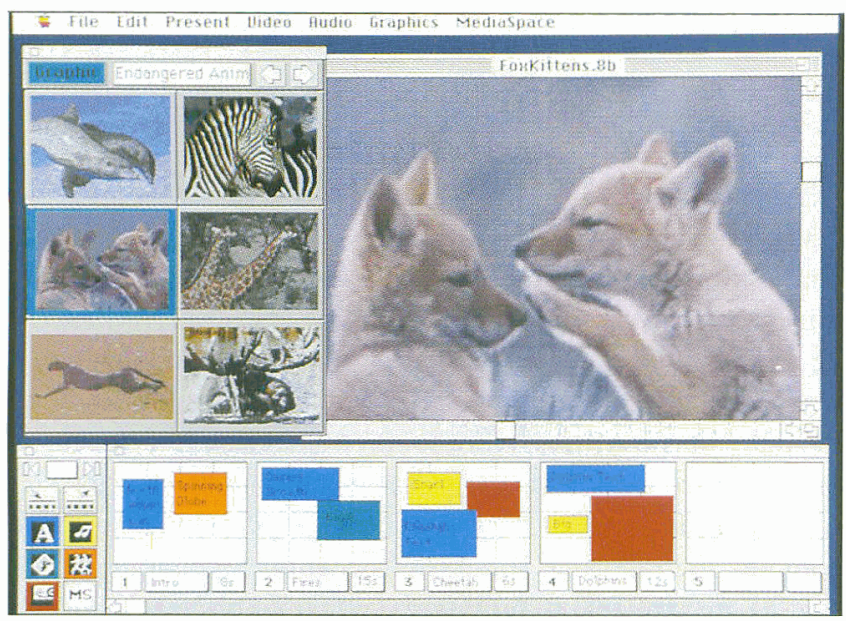

Figure 1. The Media Space interface for multimedia database browsing.

types, screen displays, and so forth) in defining the units of the hierarchy.

\section{Multimedia Works software}

The Multimedia Works software environment consists of three programs: Media Space, a multimedia database and research program; Multimedia Works Composer, a storyboarding and presentation program; and Video Light Table, a direct manipulation video-clip editor.

We initially designed Media Space and Multimedia Works Composer in Hypercard, then ported them to the Supercard environment to take advantage of the color and multiple windowing capabilities it offered. Supercard features, such as menu and window type controls and resource handling, greatly simplified the software development process and improved the user interface.

\section{Media Space}

Media Space currently consists of more than 500 text, graphic, sound, animation, and video elements that can be searched using key words or browsed using a visual index. This database occupies approximately 30 Mbytes on a local hard disk. Media Space is made up of a variety of search and editing tools coupled with a multimedia database of digitized elements. The media elements serve as a resource for students' explorations of environmental topics such as climatic change, pollution, and endangered species. Students can browse through a variety of color pictures and black-and-white graphics, listen to samples of digitized sounds, read a variety of topical news stories from diverse journalistic and reference sources, or view a more limited selection of digital animations and video clips (analog sources).

Students use Media Space in Multimedia Works both as a research tool to browse (as in Figure 1) or systematically to search (Figure 2) a wide array of photographic images, graph-

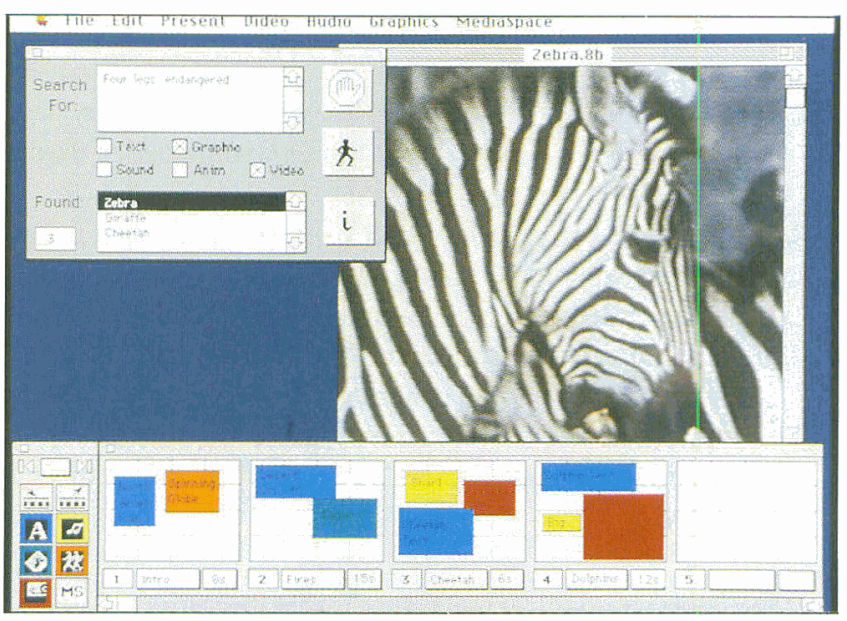

Figure 2. The Media Space interface for multimedia database search.

ics, selected readings, and digitized sounds. They also use it as a source of media in composing (with Multimedia Works Composer, represented in the storyboard at the bottom of Figures 1 and 2). Students access Media Space from the media palette (Figure 1).

Users can add media to Media Space with relative ease. Text can be typed in, downloaded electronically (using Compuserve or Dialog, for example), or taken from typewritten or typeset material using a scanner and text recognition software. Users can use a color scanner to digitize images, import them from other computer graphics applications, or digitize them from a video source. Using Farallon's Soundedit, hypermedia composers can also digitize sounds (which we have found easy enough for children to do).

\section{Multimedia Works Composer}

The heart of Multimedia Works, the Composer, is a powerful, easy-to-use multimedia composition and presentation tool. Multimedia Works Composer presents the user with a storyboard of 15 panels or media "scenes." A Multimedia Works composition consists of a number of such scenes to be played over time. Within the scenes, icons that represent media displays of different media elements are arranged spatially (Figure 3). A live storyboard of movable and editable media icons represents the document "filmstrip" made up of these scenes.

With tools to arrange media elements spatially and temporally, the Composer helps the user design the composition. Typically, students begin a new composition with a blank storyboard, then add different media elements to it by searching the Media Space database for appropriate elements. They also typically create their own elements with text and paint/drawing tools native to the Multimedia Works environment. They can create their own video clips (with the Video Light Table, described later), sound clips (with Soundedit), and animation (Macromind Director). Students can select these 


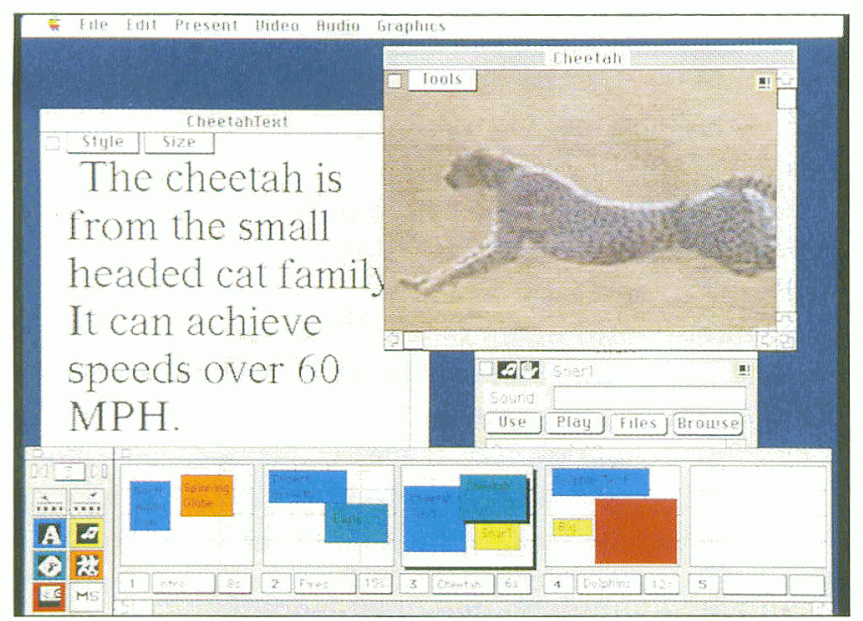

Figure 3. The Multimedia Works Composer storyboard for design of multimedia documents.

tools from a menu within the Composer and then import the media files produced into their composition.

Students create media elements by clicking on one of the five media type icons on the media-creation palette (shown in Figure 3). For example, a user creating a text element is led through a dialog box process to (1) name the text card; (2) choose its scene; (3) create the text; and (4) change the text style or size.

Using the controls in the top left of the media palette, users can add media elements or delete them from a composition by placing them in the storyboard's numbered scenes. Once placed, the elements are represented by small icons called Media Boxes, which are color-coded to distinguish the media types. Each media element's name appears on its colored Media Box. A scene can be viewed by clicking its numbered button, which highlights the border of the selected scene. Each media element in that scene is then displayed behind the foreground of the live storyboard (see Figure 3). Users can reposition, crop, or enlarge the media elements in a scene to the desired size by directly manipulating the colored Media Boxes within the scene outline. Students can easily learn this technique of one-to-one mapping of storyboard icon to media element. The direct manipulation paradigm for human-computer interface design influenced its conception. ${ }^{6}$

Users can also move media elements from scene to scene by dragging the Media Boxes from one scene to another in the scene outline. Users can play active elements such as sounds, videos, and animations by clicking on the media-distinctive "play" icon represented on the upper left corner of the element (Figure 4). Users can edit any media element by changing the style of its window from a display window to a fuller editing window, exposing the (limited) editing tools available for each type of media. For example, with text, users can control the font type and size. With sound, they can control the number of times (and with what volume) a sound will play when clicked. Double-clicking on its screen display changes the window style of a

\section{Dolphins are currently threatened by abusive fishing techniques.}

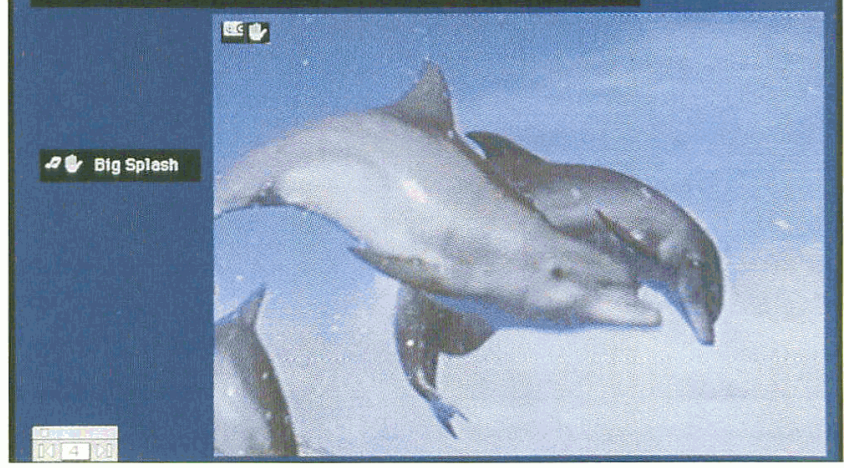

Figure 4. A display scene from a Multimedia Works document, with play icons for the sound and video elements of that scene.

media element from a display view to an edit view, and clicking on the button located in the upper right corner of that element's edit view window returns it to display view.

Three different processes present the composition. A standard method of using the Composer involves moving back and forth between scene design and viewing the media elements for that scene. Users design the scene on the storyboard and view the media elements for it on the display that appears behind it. To move from composing with the storyboard to presenting the scenes requires only a keystroke (down- or up-arrow key) to make the menu bar and storyboard disappear (or reappear). Right and left arrow keys are then used to navigate through scenes. The second presentation method employs the videolike controls on the media palette to step through or rewind the scene displays. The final method is to click the numbered buttons for each scene on the storyboard in succession.

For elements such as video clips, control palettes let you play these on an adjacent monitor (or in a video window on the Macintosh when using the Mass Microsystem's Colorspace IIi/FX videographics board). You can also use other commercial software programs in conjunction with Multimedia Works (see sidebar).

\section{Video Light Table}

Users can access the Video Light Table program under the video menu of the Multimedia Works Composer. We developed it because - unlike text, graphics, and sound - there were virtually no easy-to-use video editors available for the Macintosh environment. (Recently, Macromind announced Media Maker, which has some of these capabilities, and Digital F/X announced Video F/X, which combines video hardware and software for middle-end professional editing. The more expensive Avid system includes extensive use of image compression software for digital video storage.) We first developed the Video Light Table for use with the Pioneer 4200 videodisc 
player. It also has drivers for Sony control-L protocol to allow for the common use of logging and editing $8 \mathrm{~mm}$ and VHS videotapes.

The user interface presents a log of the video as a spreadsheet of cels, as on a conventional light table (see Figure 5). In each cel, a digitized frame serves as an icon for that segment of videotape and includes start and stop times for the video segment. Users control player and recorder control panels and buttons for video digitization and assembly edits from a floating palette. Users can also sequence video segments (for either playback or recording) by spatially sequencing the video cels in the order they wish to view or record. To rearrange the temporal order of the segments, the user simply grabs the cels with the mouse and moves them to the desired location. The Video Light Table window displays the change.

\section{Participatory design in learning}

In developing a learnable set of multimedia tools, we began our effort with the following foundations:

- We focused on learner-centered environment design, which is emerging as a critical need from learning research in the cognitive and social sciences. ${ }^{7}$

- We focused on an iterative, participatory design process for our tools and materials. In this process, we considered ethnographic observations of software use for real activities and user involvement in design as critical for creating a fit between tool and tasks. ${ }^{8,9}$

Through their participation, students had a substantial influence on software design. They pressed for integrating the Media Space and Composer software programs, which we initially conceived of as separate tools. They continually suggested simplifications of the sequence of software operations that they had to go through to create media or design a composition. They led us to eliminate many functionalities we thought might be good ideas (such as special effects and dissolves between scenes); they did not perceive these functionalities as "core" to their design and production tasks.

\section{Phase 1: Multimedia Works boys' club}

Four different phases made up our Multimedia Works learning research. In May 1989 we began the first phase. With a boys' club of about eight adolescents in a local middle school from an underserved community, we started with preliminary designs in a rough Supercard prototype. The club met two afternoons each week for two hours until December 1989. Our objectives were to establish workable activities that would sustain the boys' interests, give us good feedback on the learnability and appropriateness of the tool's design for their needs, and suggest learning topics and activities.

\section{Multimedia Works Hardware and Software Specifications}

One media-creation/presentation station supports three composition stations. We recommend two media-creation/presentation stations together with six composition stations for a classroom's lab. Additional Multimedia Works stations consisting of a Macintosh II with 8 Mbytes of RAM, an 80-Mbyte hard disk drive and a 13-inch color monitor can share the audiovisual hardware.

Other requirements for the creation of Multimedia Works presentations include videotape and laser discs as media sources, blank media (diskettes, videotapes, and so forth) and electrical, video, and audio cabling plus the VPC cables to access the Control S and Control $L$ ports on a VCR from a Macintosh computer.

\section{Multimedia Works Station Hardware:}

1. Macintosh 11 with 8-Mbyte RAM and 80-Mbyte

hard disk drive

2. 13-inch color monitor

3. 13- inch multiscan monitor (for example, the Sony CPD 1302, if videographics board is not used)

4. 45-Mbyte cartridge hard drive (recommended for receiving upgrades and for exchanging digital compositions), plus three to four blank cartridges

5. Colorspace Graphic Overlay Board (Mass Microsystems)
6. Colorspace FX Video Board (Mass Microsystems)

7. Laserdisc player level III (for example, the Pioneer 4200)

8. Sony $8 \mathrm{~mm}$ VCR with 5 -pin control port for video input (such as EV-S900)

9. Self-powered speakers (or TV monitor with speakers)

10. Copy stand and color video camera for digitizing images

11. Lavalier or Super-Directional microphone for narration

12. Video cassette recorder for recording output of presentations (such as the Sony SLV-757)

13. $8 \mathrm{~mm}$ video camera for recording video input

Software for each station (in addition to Multimedia Works software):

1. Macintosh Operating System 6.07

2. Supercard version 1.5 (Silicon Beach)

3. Smart Scrap Desk Accessory (Solutions International)

4. Soundedit and Macrecorder (Farallon) for sound digitizing

5. Director (Macromind) for creating animations

6. Colorspace Init \& DA's: Driver, Desktop Video, NTSC Digitizer 
Students developed multimedia compositions on their topic and presented them to other teams of students to explain, tell a story, or persuade. They spent about four to six weeks collaboratively researching and preparing presentations on a variety of topics in environmental science. At the conclusion of each cycle, they presented their work to their peers and recorded their presentations on videotape to take home or to school. Through this approach, students who created the compositions learned about both the subject matter and how to effectively communicate using written text integrated with other media such as graphics and video.

While you can use the Multimedia Works tools for virtually any topic, students' work examined issues in environmental science, including science, technology, and society issues like global warming, toxic wastes, and species depletion. Small groups of students researched and collected various media including newspaper articles, magazine illustrations, television documentaries, and their own video and audiotapes of field trips and interviews. With some guidance, students learned to employ critical thinking skills while conducting their own discussions. They learned to analyze the media they had collected, focus on their chosen topic, and select and organize the media to communicate their ideas. The computer tools then helped in composing texts, graphics, video, and sounds into a presentation.

\section{Phase 2: Multimedia Works girls' club}

One major change occurred when we began to work with a dozen middle school girls in a similarly organized club. We did more group work in planning the compositions; we spent more time researching, defining, and designing the media used in them. As with the boys' club, we focused on critical and goal-directed media use. But we had a new objective: to have students work on the use of argumentation and persuasion within the composition. We highlighted the importance of developing arguments that present evidence both for and against one's position. We also stressed the importance of weighing these considerations on behalf of the argument presented. ${ }^{10}$

The full group worked to brainstorm, choose composition topics, and divide up research work to define relevant media for potential use in their compositions. Refinements of design work and decisions were made in groups of two to three students.

In their first group work, the students composed a multimedia composition arguing against the planned construction of office towers in their downtown area. The presentation included digitized maps, graffiti artwork, traffic noises, newspaper sketches of the proposed structure, notes from interviews with neighbors on their perceptions of the development project, a video clip of an interview with a local realtor whose office would be displaced by the construction, and a videotaped speech on the group's beliefs, co-authored by the group but presented by one student. The students went on to develop compositions on topics such as the plight of various endangered species and their favorite popular music groups.

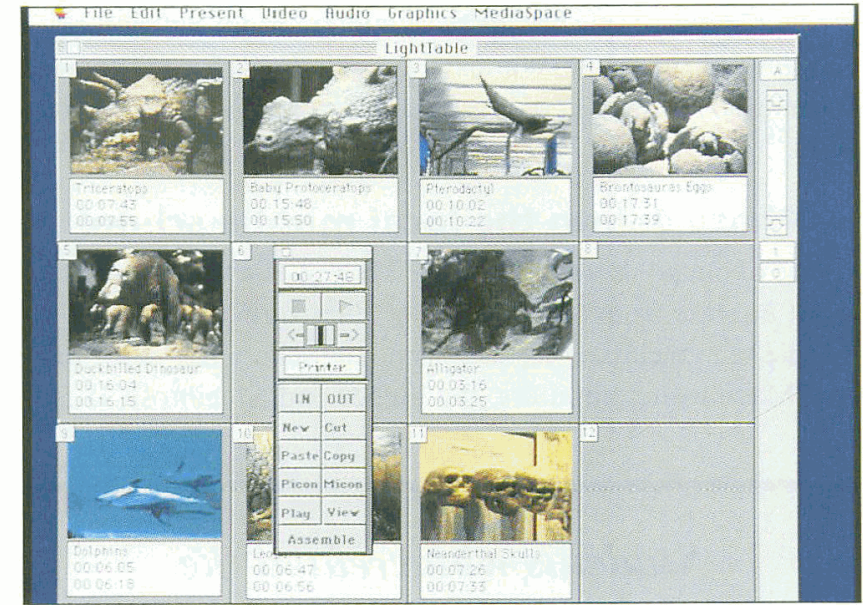

Figure 5. The Video Light Table Interface for video clip selection and assembly editing.

A fundamental improvement in the girls' club was the regular use of "design crits." Peers and researchers viewed an early draft of a multimedia composition and then offered constructive criticism of it. Specialists and experts on the topic the composition covered also joined in on some of these critiquing sessions.

\section{Phase 3: IRL summer work}

Enrique Godreau and Michael Chertok of the Multimedia Works Project ran an intensive research activity in July and August 1990. The Stanford Youth Employment Program provided funding for five students who had just graduated from the same middle school from which our club students had come. They worked for 20 hours a week at the Institute for Research on Learning on a number of Multimedia Works activities:

1. They created Multimedia Works compositions on how to use Multimedia Works, planned for use as training materials at the middle school in fall 1990.

2. They designed a report to the National Science Foundation using Multimedia Works. The report provided multimedia rationale and documented the research perspectives, software, and classroom-based research findings for a project on learning physics.

3. They created some open-choice documents, which included an impressive analysis of recent media events, such as flag-burning and the banning of rap-music lyrics, as tests of First Amendment rights.

During the same period, a number of teachers from the students' former school also came to IRL. They came to learn to work with the Multimedia Works software and rethink their media use in the classroom in terms of what the technology makes available (an effort supported by a Carnegie Corporation grant). This studio environment, in which students and 
teachers worked side by side (without the traditional authority relations of the school context), provided a rich environment for mutual learning in their respective research and design efforts. $^{10}$

\section{Phase 4: Into the local middle school}

One of our goals was to have the Multimedia Works environment migrate from an after-school club to regular use within middle school classrooms. But while the school had some lowend Macintosh computers, the higher-end Macintosh II and

\section{Students who created the compositions learned about both the subject matter and how to effectively communicate using written text with graphics and video.}

multimedia add-ons our software required were not available. Godreau and Chertok at IRL worked collaboratively with a development specialist from the school district on an Apple Computer Crossroads Grant application that would enable the school to support the transformation of its classrooms into multimedia studios that students and teachers could use as an integral part of their learning and teaching. The school serves more than 400 seventh and eighth grade students. This Apple Computer grant program is a competitive one, and schools must provide substantial evidence that they are at a "crossroads" in how they approach educational processes. In the case of our partner middle school, they were in the midst of a transition into "thematic instruction," an approach that combines formally distinct disciplines such as history, English, and social studies (or mathematics and science) through such activities as team teaching, project work, and longer class periods. The grant application succeeded, and in fall 1990, Multimedia Works began in earnest at the middle school.

Teacher training in summer 1990 and fall 1990 for the schoolbased Multimedia Works Project consisted of three components:

1. basic computer skills and general operation of Macintosh computer equipment;

2. multimedia production skills, including the use of specialized software and the operation of video and audio equipment; and

3. integration of multimedia production with the classroom curriculum.

The supervised practice in multimedia production was the most extensive portion of the training and consisted of helping pairs of teachers create two multimedia compositions to present in their own classrooms. Training included an exhibition of sam- ple multimedia presentations, practice in the use of the software, instruction and practice in the use of audio and video equipment with particular emphasis on use of the video camera, supervised (and unsupervised) composition time, and group critiques of compositions in progress.

\section{Working with multimedia tools}

Since regular student multimedia activities began last fall, students have been filling the lab before and after school, at lunch, and between periods. I can briefly describe what the students have been doing by characterizing their processes of working with the multimedia tools:

1. Student teams are organized and assigned a topic. They discuss their topic and begin research using traditional resources such as newspapers, magazines, and encyclopedias. They also browse through the collection of images, text articles, sounds, and graphics that the teacher has assembled in the Media Space database.

2. Students take field trips, visit museums, and do homework assignments to gather media for their composition. In a project on endangered species, for example, students might videotape scenes at the zoo, record an interview with an environmental scientist working on these problems, use their VCR at home for recording a special news report on related topics, or find pictures of animals in books or a museum directory.

3. Student teams examine their collection of media, logging the contents of video and audio tapes and assembling the media they want to use to present their topic. An important part of this process is analyzing the media they have collected, that is, determining what a particular quote, picture, or video segment really conveys. The teams then begin to design and refine their media to plan an effective presentation.

4. Members of each team assume roles needed for the production of their presentation. Some of the primary roles include researchers, directors, storyboard planners, writers, graphic artists, designers, video producers, and audio producers. As a team, students plan the structure of their presentation using a sloryboard.

5. The teams bring their media to the Multimedia Works composition station and begin to assemble their presentation. In the process of composition, the students continue to analyze the media they have collected, gather additional media, and refine the writing and organization of their presentation.

6. Once a first draft of their composition is ready, the student team critiques their own work together with their teacher and other participants who have special knowledge of the topics involved. Students create a list of what they want to do differently. The teams continue to revise their compositions.

7. Students share their multimedia compositions with other students in the class and record their revised presentation on videotape. Students answer questions and lead discussions regarding their work.

8. Students can present their work in other classes, in other 
schools, or in a community forum. The videotaped presentations can be kept in a library collection of student-produced learning materials.

\section{Some principal challenges}

Certain issues are central to the successful use of Multimedia Works. These issues tend to lie at the intersection of technology design and user support for learning activities, and we are working on these challenges now:

1. At first, students often have difficulty comprehending the spatial representation of temporal media and distinguishing "plans" for compositions (that is, the live storyboard) from the compositions themselves. This would improve if a time-based controller for media displays within the Composer scenes on the Macintosh were possible. Currently, audio, video, and animation displays make synchronization a technical barrier.

2. While "closed" databases pose severe limitations for learning (students have to repurpose video, sounds, and so forth in their compositions), an approach that empowers students to extend such databases is not without its own problems. Moving toward multimedia-database extensibility by learners includes

- A difficulty in coming to "see" other media segments as data for use in a multimedia composition (that is, to conceive of part-whole relations). Students' experiences of passively viewing TV and listening to music clashes with multimedia, where students can "capture" some segment of what they see or hear for subsequent use in a composition. The capacity for learners to use devices to capture live media such as audio and video is quite novel. These media distinguish multimedia compositions from writing and spur students' imaginations in ways uncommon in text-centered composition.

- Attribution of media. New practices, somewhat akin to library scholarship, need to become a standard part of media use ethics by students. Otherwise, copyright issues will become a problem. Students do not always take the time to make references and attributions to the media they find or to cite other students' media contributions to their work.

3. Although small-group learning activities are highly recommended in classroom learning research, getting our club participants to make reliable commitments and follow through to doing subparts of a larger multimedia development project proved difficult. The Multimedia Works software environment currently does not explicitly support project planning and monitoring activities. Often we need to request volunteers to do some component task of the larger project. Even with external guides to the part-task relation to the whole (such as a large white board that specifies a "storyboard" for the plan), the movement of students into subtask groups and the monitoring of progress toward these can be very hard to sustain. Part of this problem might have resulted from the club nature of the research.

4. Multimedia might fundamentally change the nature of learning by creating rich conversational artifacts for discussion and presentation. To use the full expressive powers of different media, old molds of teaching and learning must be broken. One risk we fear is that multimedia technologies will be seen as sophisticated word processors. Rather than changing learning practices, they will fit into current systems of teaching, testing, and evaluation, thus perpetuating educational practices now under national critique.

5. Network support for collaborative activity in designing and critiquing Multimedia Works documents is desirable, but

\section{An important part of multimedia composing is analyzing the media you have collected, that is, determining what a particular quote, picture, or video segment really conveys.}

such support lies beyond the current budgetary possibilities of both the school and the project's developers.

\section{Implications}

The research contributions of the Multimedia Works Project reside in the timely investigation of the educational opportunities and cognitive problems of multimedia. Our results indicate that we can easily make multimedia composition accessible to middle school students. The tools and activities promote rethinking cross-curriculum relationships and what students do to learn. We hope the "plan for success" project philosophy, exemplified in its formative research and participatory design methods, will result in a replicable model for student collaboration and small-group learning with multimedia.

Through the successes of this project, we hope to persuade researchers to develop tools for students to use for creating multimedia compositions. Students quickly learn to create such compositions and find the process engaging and motivating. We also hope to see educators using such learner-centered multimedia in the classrooms of the future.

We set out to support the choreographic sequencing of multimedia document elements in space and time. While the Multimedia Works interface provided clear support for these tasks, more time-precise displays of multimedia document elements pushed the current Macintosh platform's capabilities. Students are demanding in this respect-they are accustomed to MTV and commercial film timing and rhythm and want their displays to reproduce these real-time effects. If we begin to think of the child's desktop as the frontier of advanced computing rather than a trickle-down from military and industrial technologies, then the students might get their wish. 


\section{Acknowledgments}

The project and software were formerly known as "MediaWorks." Roy Pea created the project, and with Ed Boyle provided basic interface design for the Multimedia Works environment. Ed Boyle has been the principal programmer, with significant contributions from Enrique Godreau (Xerox Social Service Fellow) and Neils Veirum (Aalborg University, Denmark). Christina Allen, Chertok, and Godreau were instrumental in planning and conducting club activities. Other collaborators in Media Works research and development include Kathy Adams, Nancy Allen, Amitabh Ashesh, Isaac Jackson, and Jerome Shaw. Apple Computer's ACOT Project has supported the development of the Media Works prototype, and hardware for the project was provided by Apple Computer (External Research) and Farallon Computing, with some equipment support from Xerox Corporation. Partial support of the Science Media Works Club came from a contribution of the Carnegie Consortium Toward the Scientific Practice of Science Education, based at IRL and funded by the Carnegie Corporation. Student transporlation was supported by the Hewlett Foundation. We especially thank our club participants for their participatory design efforts. Our colleagues at IRL were also helpful. This project began in February 1989. Presentations of some of this work have been made to conferences of the American Educational Research Association, $\mathrm{CHI}-$ 90 invited poster, Computer-Using Educators (CUE), Mac World 90 , Siggraph Hypermedia Exhibit, and the Social Science Research Council Workshop on Social Aspects of Computing.

\section{References}

1. S.M. Eisenstein, Film Sense, Harcourt Brace Jovanavich, New York, 1947.

2. R.D. Pea, "Human-Machine Symbiosis: Exploring Hypermedia as New Cognitive and Cultural Technologies," to be published in Cognition, Computers and Epistemology, K. Plunkett and S.F. Larsen, eds. Lawrence Erlbaum Associates, Hillsdale, NJ.

3. R.D. Pea, and D.M. Kurland, "Cognitive Technologies for Writing Development," in Review of Research in Education, E. Rothkopt, ed., 1987, pp. 71-120

4. R.D. Pea, E. Boyle, and R. de Vogel, "Design Spaces for Multimedia Composing Tools," in Designing for Learning, B. Bowen, ed., Apple Computer Press, Cupertino, Calif., 1990.

5. M. Mills, and R.D. Pea, "Mind and Media in Dialog," to be published in Full Spectrum Learning, K. Hooper and S. Ambron, eds., Apple Press, Cupertino, Calif.

6. J. Hollan, E. Hutchins, and D. Norman, "Direct Manipulation Inter faces," in User-Centered System Design, D. Norman and S. Draper. eds., Lawrence Erlbaum Associates, Hillsdale, NJ, 1987.

7. R.D. Pea and E. Soloway, "Mechanisms for Facilitating a Vital and Dynamic Education System: Fundamental Roles for Education Science and Technology," Rept. to the Office of Technology Assessment (National Tech. Information Service Rept. PB 88-194 634/AS), 1987.

8. C.L. Allen, "Reciprocal Evolution: A Design and Research Strategy for the Development and Integration of Basic Research, Design, and Studies of Work Practices," to appear in Participatory Design, D. Schuler, ed., Lawrence Erlbaum Associates, Hillsdale, N.J.

9. P. Ehn, Work-oriented Design of Computer Artifacts, Almquist and Wiksell Int'l, Stockholm, Sweden, 1988.

10. C.L. Allen, "Multimedia Learning Environments Desighned with Organizing Principles fron Non-School Settings," to be published in NATO Advanced Research Workshop on Computer-based Learning Environments and Problem-Solving, E. De Corte, et al., eds., SpringerVerlag, New York.

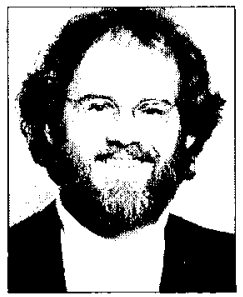

Roy D. Pea is a senior research scientist at the Institute for Research on Learning and a consulting professor at Stanford University. He is a cognitive scientist with special interests in integrating research and the design of effective learning environments for science, programming, and multimedia computing. In September 1991, he will become John Evans Professor of Education and the Learning Sciences at Northwestem University. Pea received his D.Phil. in developmental psychology at Oxford University. He is a member of the American Educational Research Association, the Cognitive Science Society, the American Psychological Association, and SIG CHI.

Readers may contact Pea at Institute for Research on Learning, 2550 Hanover St., Palo Alto, CA 94304. 
Copyright (C) 1991 The Institute of Electrical and Electronics Engineers, Inc. Reprinted with permission from IEEE Computer Graphics and Applications. 10662 Los Vaqueros Circle, Los Alamitos, CA 90720 